\section{ENAMEL-BOOSTING SERUM OFFICIALLY LAUNCHED}

BDJ Managing Editor Dr Ruth Doherty is pictured (right) at the official launch of Unilever's REGENERATE Enamel Science, a new dental care system proven to reverse the enamel erosion process. Ruth is pictured with Dr Monica Carlile, Expertise \& Authority Global Oral Care at Unilever.

REGENERATE Enamel Science is the first and only system proven to form hydroxyapatite, with identical composition to underlying enamel mineral. The dental care system, with its

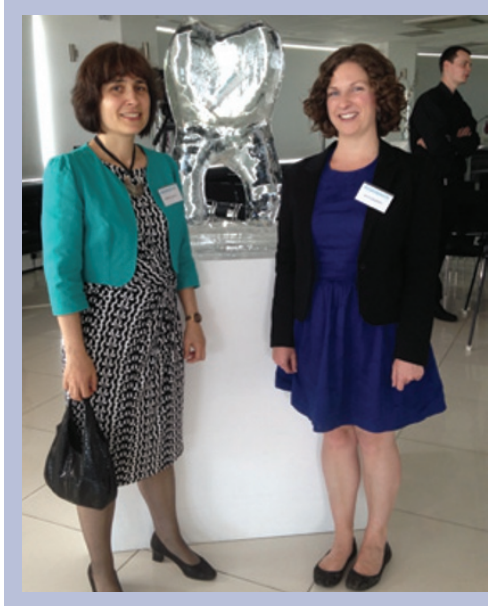

unique internationally patented NR-5 technology, helps recover $82 \%$ of enamel hardness after three days of use. A new in situ study shows that the novel technology in REGENERATE Enamel Science is effective in the mouth and is able to re-harden enamel significantly better than fluoride-only toothpaste.

Inspired by research on bone repair technology, Unilever Oral Care scientists carried out both in vitro and in situ studies, which proved that calcium silicate can deposit onto sound and eroded enamel. Upon this discovery, the novel NR-5 technology was developed to augment the natural mineralisation processes of human saliva by providing a combination of calcium silicate and sodium phosphate, which help to form a fresh supply of hydroxyapatite that wraps and integrates onto teeth.

The REGENERATE Enamel Science system consists of an Advanced Toothpaste for daily brushing and a Boosting Serum (with two custom-fit mouth trays) for application at home, monthly for three consecutive days. When used in combination with the daily Advanced Toothpaste, the Boosting Serum increases the Advanced Toothpaste effectiveness by $43 \%$, enhancing the power of enamel regeneration.

The scientific studies have been published in the June supplement of the Journal of Dentistry. A link to these studies can be found on the REGENERATE Enamel Science website: www.RegenerateNR5.com.

\section{CPD OPPORTUNITIES FOR THE WHOLE TEAM}

The Wrigley Oral Healthcare Programme has launched three new CPD modules, just in time for many dental care professionals (DCPs) seeking to secure their 50 hours of verifiable CPD before the 31 July deadline.

Wrigley has partnered with dental hygienist and nutrition expert Juliette Reeves to author two new CPD modules. Saliva and Oral Health Part 1: Maintaining Oral Health - Preventing Dental Disease will help dental professionals understand the vital part saliva plays in preventive dentistry and current thinking on the impact of saliva on oral health. A further module from Juliet: Oral and Systemic Health Implications of Saliva explores the latest research surrounding the role of saliva in nutrition and systemic and psychological wellbeing.

Those who missed the lecture from Chief Wrigley Scientist, Mike Dodds, at the Clinical Innovations conference earlier this year, have the opportunity to catch his talk: The ticking time bomb - could changes in eating behaviours cause increased caries? The lecture recording is now available to view along with 12 questions to answer for 1.5 hours of verifiable CPD.

To access all of the CPD opportunities Wrigley has to offer, go to www.wrigleyoralhealthcare.co.uk.

\section{LATEX FREE LA}

Xylocaine Standard from DENTSPLY is the first choice for GDPs and dental nurses requiring the adrenalinebased local anaesthetic and is now available latex free.

DENTSPLY aims to support the dentist in helping avoid any potential allergic reactions in patients who require local anaesthetic, thus ensuring a more comfortable dental experience. What's more, latex free Xylocaine Standard is the most competitively priced, value for money local anaesthetic available.

For more details contact DENTSPLY UK on 0800072 3313 or visit the website: www.dentsply.co.uk.

\section{KEEP TEETH HEALTHY FOR LIFE}

Curaprox has developed a range of high quality oral hygiene products to keep teeth healthy for a lifetime.

Renowned for removing plaque effectively and without trauma from round the gum-line, the CS5460 ultra soft toothbrush is ideal for use with orthodontic appliances.

Featuring a unique bracketfriendly groove and slightly angled head, the 5,460 individual $0.1 \mathrm{~mm}$-fine CUREN filaments provide an unparalleled cleaning surface on an extremely compact head. The hexagonal handle helps to brush at the correct angle and enables easy access to effectively clean all parts of the mouth.

To complement and enhance the CS5460, Enzycal is a mild anti-caries toothpaste with gentle SLS-free formula for everyday use. With sodium fluoride to strengthen enamel, patients can ensure a gentle yet thorough clean every time.

The CS5460 toothbrush and Enzycal toothpaste are just part of the Curaprox range of premium healthcare products available, which includes interdental brushes, the Hydrosonic toothbrush and CURASEPT ADS (Anti-Discolouration System) mouthwash.

For more information call 01480 862084 or visit www.curaprox. co.uk.
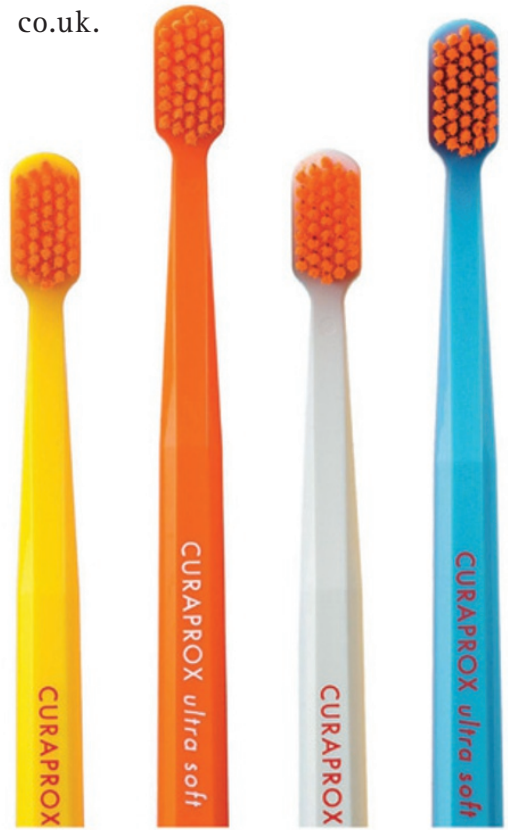